Disclosures A. Paul: None. J. MacDonell: None. N. Field: None. P. Entezami: None. J. Dalfino: None. A. Boulos: None.

\section{E-061 DELIVERY OF A NOVEL 8F ASPIRATION CATHETER TO THE INTRACRANIAL VESSELS IN A FRESH-FROZEN CADAVER MODEL}

${ }^{1} \mathrm{R}$ Nogueira* ${ }^{2} \mathrm{~L}$ Mullins, ${ }^{2} \mathrm{D}$ Finneran, ${ }^{3} \mathrm{~W}$ Allen, ${ }^{4} \mathrm{~J}$ Thornton. ${ }^{1}$ Neuroendovascular Service Marcus Stroke and Neuroscience Center, Grady Memorial Hospital and Emory University, Atlanta, GA; ${ }^{2}$ Perfuze Ltd, Galway, IRELAND; ${ }^{3}$ Perfuze Ltd, Galway, GA; ${ }^{4}$ Interventional Neuroradiology, Beaumont Hospital, Dublin, IRELAND

\subsection{6/neurintsurg-2020-SNIS.97}

Introduction/Purpose Larger lumen catheters are associated with improved reperfusion using aspiration for the treatment of stroke. Significant scope remains to improve the rate of first pass effect, which has been associated with significantly improved clinical outcomes. To date, the degree of tortuosity encountered during neurovascular procedures has limited the ability of larger lumen catheters to navigate distally to the target vessels. Perfuze Ltd (Galway, Ireland) have developed a novel aspiration catheter (Millipede 088) which has an $8 \mathrm{~F} \mathrm{OD}$ and 0.088 " ID. The purpose of this study was to evaluate the navigability of Millipede 088 to the M1 segment of the MCA in a fresh-frozen cadaver model.

Methods In total six cadavers were investigated, allowing evaluation of navigation to twelve MCAs. Commercially available 6F aspiration catheters (Terumo Sofia Plus, Penumbra ACE 64 and 68) were used as a control for baseline comparison. Slow perfusion using warm water was maintained throughout the procedure. The study was conducted at MERI, Memphis, TN, USA, using Siemens Artis Pheno for imaging.

Control A Penumbra Neuron Max was placed at the petrous segment of the ICA. The $6 \mathrm{~F}$ aspiration catheter was navigated triaxially over a microcatheter and microwire. Initially, $2.1 \mathrm{~F}$ microcatheters and 0.014 " microwires were used for support. Where additional support was required, microcatheters of up 2.7F or Penumbra 3Max and/or a 0.016 " microwire were used. Test: Via femoral access, an $80 \mathrm{~cm}$ long sheath Super ArrowFlex (Teleflex) or Flexor Shuttle (Cook) was placed in the 
proximal ICA. Various combinations of internal support were investigated 1) $2.1 \mathrm{~F}$ microcatheters and 0.014" microwire, 2) $6 \mathrm{~F}$ aspiration catheters. Where additional support was required to cross the ophthalmic artery, microcatheters of up $2.7 \mathrm{~F}$ or Penumbra 3Max and/or a 0.016" microwire were used.

Results Varying tortuosity was encountered; aortic-arch (Type IIII, bovine), cervical (s-shaped); siphon (U, C, S, $\Omega$ ). In 11/12 instances it was possible to navigate to the distal M1 using test (Millipede 088) and control (6F aspiration catheters) devices. In the instance of unsuccessful navigation, both Millipede 088 and the $6 \mathrm{~F}$ aspiration catheters were unable to cross the ophthalmic artery. In general, navigation of Millipede 088 to the M1 was facilitated by the support of a $6 \mathrm{~F}$ aspiration catheter.

Conclusions Navigation of the Millipede 088 catheter to the M1 is feasible in a cadaver model. The ophthalmic artery can represent a challenge which in the majority of cases can be overcome using the support of standard neurovascular devices. Disclosures R. Nogueira: 2; C; Perfuze Ltd. 4; C; Perfuze. L. Mullins: 4; C; Perfuze Ltd. 5; C; Perfuze Ltd. D. Finneran: 4; C; Perfuze Ltd. 5; C; Perfuze Ltd. W. Allen: 4; C; Perfuze Ltd. 5; C; Perfuze Ltd. J. Thornton: 2; C; Perfuze Ltd. 4; C; Perfuze Ltd.

\section{E-062 IMPACT OF ANGIOGRAPHIC APPEARANCE OF PROXIMAL MIDDLE CEREBRAL ARTERY OCCLUSION ON FIRST PASS REPERFUSION}

M Mohammaden*, D Haussen, L Pisani, A Al-Bayati, S Belagaje, N Bhatt, M Frankel, R Nogueira. Marcus Stroke and Neuroscience Center, Grady Memorial Hospital and Department of Neurology, Emory University School of Medicine, Atlanta, GA

\subsection{6/neurintsurg-2020-SNIS.98}

Background and Purpose The first pass effect (FPE) is a key predictor of clinical outcome after mechanical thrombectomy (MT) for large vessel occlusion stroke (LVOS). We aim to study the impact of initial angiographic appearance of middle cerebral artery (MCA) occlusion on FPE.

Methods A prospectively maintained MT database from January 2018 to December 2019 was reviewed. Patients with M1 segment MCA occlusion were included. FPE was defined as complete reperfusion (mTICI2c-3) after a single pass thrombectomy. Occlusion site angiographic appearance was classified into two categories; regular, when the occlusion is smooth stump with abrupt cut off and irregular which included all other types of occlusion. The primary outcomes were the

Abstract E-062 Table 1 Demographic, risk factors, procedural characteristics and outcome among regular and irregular MCA occlusion

\begin{tabular}{|c|c|c|c|c|}
\hline & All patients $(n=319)$ & Regular $(n=130)$ & Irregular(n=189) & $P$ value \\
\hline \multicolumn{5}{|l|}{ Demographics and stroke risk factors } \\
\hline Age & $65.1 \pm 16.1$ & $64.4 \pm 15.5$ & $65.7 \pm 16.5$ & 0.50 \\
\hline Female & $168(52.7)$ & $68(52.3)$ & $100(52.9)$ & 0.92 \\
\hline Hypertension & $243(76.2)$ & $101(77.7)$ & $142(75.1)$ & 0.60 \\
\hline Diabetes mellitus & $85(26.6)$ & $33(25.4)$ & $52(27.5)$ & 0.67 \\
\hline Atrial fibrillation & $103(32.3)$ & $43(33.1)$ & $60(31.7)$ & 0.80 \\
\hline Hyperlipidemia & $89(27.9)$ & $40(30.8)$ & $49(25.9)$ & 0.34 \\
\hline Current smoking & $72(22.6)$ & $37(28.5)$ & $35(18.5)$ & 0.037 \\
\hline Stroke etiology Cardioembolic & $152(47.6) 30(9.4)$ & $69(53.1) 10(7.7)$ & $83(43.9) 20(10.6)$ & 0.04 \\
\hline Large artery disease ICAD Others & $31(9.7) 106(33.2)$ & $6(4.6) 45(34.6)$ & $25(13.2) 61(32.3)$ & \\
\hline \multicolumn{5}{|l|}{ Clinical and procedural characteristics } \\
\hline LKN-Puncture & $394[217-737]$ & $442[217-726]$ & $379[211-754]$ & 0.99 \\
\hline Baseline NIHSS score & 17 [12-21] & 18 [12-21] & 17 [13-21] & 0.60 \\
\hline ASPECTS & 8 [7-9] & 8 [7-9] & 8 [7-9] & 0.24 \\
\hline Prior IV-tPA & $95(29.8)$ & $37(28.5)$ & $58(30.7)$ & 0.67 \\
\hline Favorable collaterals & $154 / 205(75.1)$ & $64 / 82(78)$ & $90 / 123(73.2)$ & 0.43 \\
\hline Left hemisphere stroke & $161(50.5)$ & $61(46.9)$ & $100(52.9)$ & 0.29 \\
\hline Tandem occlusion & $13(4.1)$ & $7(5.4)$ & $6(3.2)$ & 0.32 \\
\hline General anesthesia & 37 (11.6) & $13(10)$ & $24(12.7)$ & 0.46 \\
\hline Balloon guide catheter & $297(93.1)$ & $121(93.1)$ & $176(93.1)$ & 1.00 \\
\hline First-line technique SR CA Combined Primary intracranial stenting & $165(51.7) 43(13.5)$ & $66(50.8) 46(35.4)$ & $99(52.4) 63(33.3)$ & 0.81 \\
\hline Secondary intracranial stenting & $109(43.2) 2(0.6)$ & $18(13.8) 0(0)$ & $25(13.2) 2(1.1)$ & \\
\hline Puncture to first run & $8[6-12]$ & $8[6-12]$ & $8[6-11]$ & 0.98 \\
\hline First run to reperfusion & $35[21-59]$ & $37[21-64]$ & $33[21-53]$ & 0.14 \\
\hline Number of passes & $2[1-3]$ & $2[1-3]$ & $1[1-2]$ & 0.01 \\
\hline IA-tPA & $3(0.9)$ & $0(0)$ & $3(1.6)$ & 0.27 \\
\hline \multicolumn{5}{|l|}{ Outcome } \\
\hline $\mathrm{FPE}(\mathrm{mTICl} 2 \mathrm{c}-3)$ & $132(41.4)$ & $45(34.6)$ & $87(46)$ & 0.04 \\
\hline First pass successful reperfusion (mTICI2-3) & $154(48.3)$ & $52(40)$ & $102(54)$ & 0.01 \\
\hline Successful reperfusion at the end of the procedure & $313(98.1)$ & $128(98.5)$ & $185(97.9)$ & 1.00 \\
\hline Parenchymal hematoma type 2 & $14(4.4)$ & $9(6.9)$ & $5(2.6)$ & 0.067 \\
\hline $90 \mathrm{~d}$ mRS $0-2$ & $100(44.6)$ & $38(44.2)$ & $62(44.9)$ & 0.91 \\
\hline $90 \mathrm{~d}$ mortality & $42(18.8)$ & $14(16.3)$ & $28(20.3)$ & 0.45 \\
\hline
\end{tabular}

